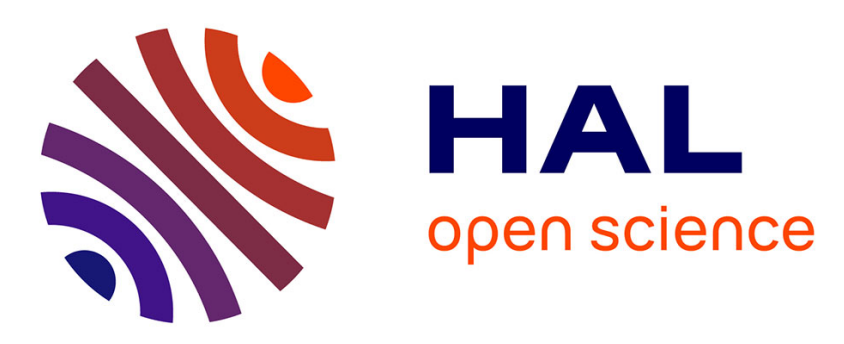

\title{
Instrumented clamping device and numerical simulations to study machining distortion
}

Iheb Cherif, Dominique Cotton, Gerard Poulachon, Jose Outeiro, Alexandre Brosse, Joana Rebelo Kornmeier

\section{- To cite this version:}

Iheb Cherif, Dominique Cotton, Gerard Poulachon, Jose Outeiro, Alexandre Brosse, et al.. Instrumented clamping device and numerical simulations to study machining distortion. International Journal of Advanced Manufacturing Technology, 2019, 105 (7-8), pp.3093-3103. 10.1007/s00170-01904510-7 . hal-02418041

\section{HAL Id: hal-02418041 \\ https://hal.science/hal-02418041}

Submitted on 18 Dec 2019

HAL is a multi-disciplinary open access archive for the deposit and dissemination of scientific research documents, whether they are published or not. The documents may come from teaching and research institutions in France or abroad, or from public or private research centers.
L'archive ouverte pluridisciplinaire HAL, est destinée au dépôt et à la diffusion de documents scientifiques de niveau recherche, publiés ou non, émanant des établissements d'enseignement et de recherche français ou étrangers, des laboratoires publics ou privés. 


\title{
Instrumented clamping device and numerical simulations to study machining distortion
}

\author{
Iheb Cherif ${ }^{1} \cdot$ Dominique Cotton $^{1} \cdot$ Gerard Poulachon $^{1} \cdot$ Jose Outeiro ${ }^{1} \cdot$ Alexandre Brosse $^{2} \cdot$ Joana Rebelo Kornmeier $^{3}$
}

\begin{abstract}
Machining part distortion is due to residual stresses induced by previous manufacturing processes. This study aims to evaluate the influence of machining conditions on AISI 316L plate distortion. Therefore, a special experimental device with force sensors integrated in the clamping system and numerical model of distortion were developed. Residual stresses due to previous machining processes were measured using a layer removal method and neutron diffraction technique. Then, distributions of these residual stresses were integrated in a developed model of machining distortion, which considers the clamping and machining sequence effects after each stage of the toolpath. A comparison of the experimental and numerical results revealed that the finite element method can adequately predict machining distortion. The results also suggest that clamping and machining sequence can affect part distortion.
\end{abstract}

Keywords Machining $\cdot$ Residual stresses $\cdot$ Part distortion $\cdot$ Numerical simulation

\section{Introduction}

Nowadays, the distortion of manufactured parts can be minimized by adjusting machining conditions. However, understanding and predicting part distortion is a key goal for many industries, including the nuclear industry. Controlling such distortions could be a manner in which productivity and the quality of manufactured parts are improved. More specifically, it could allow the design of thinner components to achieve better efficiency and performance in future nuclear reactors $[1,2]$. In this context, the machining process must be conducted using an adequate machining strategy, whose aim is to respect the geometrical characteristics of the final part.

Mannan and Sollie [3] considered that an excessive clamping force affects distortion in machining. Therefore, controlled clamping is essential for minimizing distortion

Iheb Cherif

iheb.cherif@ensam.eu

1 Arts et Metiers ParisTech, LaBoMaP, UBFC, 71250 Cluny, France

2 FRAMATOME, 10 rue Juliette Récamier, 69456 Lyon Cedex 06, France

3 Heinz Maier-Leibnitz Zentrum (MLZ), Technische Universitaet Muenchen, 85748 Garching, Germany issues [3-5]. To optimize fixture devices, $\mathrm{Wu}$ and Chan [6] studied clamping stability by implementing a kinematic fastening general model that considers the clamping force and friction. Rai and Xirouchakis [7] analyzed the thin wall part behavior during milling considering the influence of the clamping and the thermomechanical loading due to the interaction between the cutting tool and the workpiece. They observed that wedge-clamp configuration is more stable than a strap-clamp one.

In the present work, a smart clamping system was designed and then applied in machining experiments to control the magnitude of clamping in real time. A few of the benefits of this new clamping system are the prevention of any movement and the ensured stability of the sample during machining, which is possible when a fixture clamp with parallel jaws is used, as shown by Richter-Trummer et al. [8]. Furthermore, Cerutti et al. [9] considered that the fixture elements have to be located in the most rigid areas of the workpiece to avoid reflections during clamping.

The present study focuses on machining of AISI 316L austenitic stainless steel plates obtained by rolling followed by heat treatment. The aim of this work is to (1) predict part distortion after machining and (2) propose some explanations for the phenomena occurring during this process contributing to part distortion (i.e., finding a relation between residual stress distribution, part distortion, and clamping). To achieve 
these objectives, it is necessary to (1) determine the initial residual stress field induced by heat treatment; (2) develop a distortion model considering the initial residual stress field, machining clamping forces [10-13], and sequence effects (i.e., the effect of the distorted shape at a given stage on the material removal from the following machining stage); (3) design and produce a special experimental device with force sensors integrated in the clamping system; and (4) validate the numerical clamping force using this fastening device.

\section{Experimental determination of the residual stresses induced by heat treatments and part distortion induced by machining AISI 316L stainless steel samples}

Austenitic stainless steel AISI 316L samples were used in this study. The AISI 316L material is used in nuclear environments due to its particular property of good corrosion resistance. However, it is considered as a poorly machinable material due to its high work-hardening and low thermal conductivity, resulting in high cutting temperatures, which cause accelerated tool wear and poor machined surface integrity.

The microstructure of the AISI $316 \mathrm{~L}$ sample was composed of austenitic grains with an average grain size of $100 \mu \mathrm{m}$. The residual stress distributions of the samples were determined by a neutron diffraction technique and layer removal method. The samples used for all experiments have a similar residual stress distribution as they were extracted from the center of the same industrial plate whose size is $2000 \mathrm{~mm} \times$ $1000 \mathrm{~mm} \times 21 \mathrm{~mm}$. They were prepared by removing a $0.5 \mathrm{~mm}$ thick layer from the top and bottom of each sample's surface.

In this work, residual stresses are solely due to heat treatment because the residual stresses resulting from the rolling process are eliminated during an annealing treatment at $1100{ }^{\circ} \mathrm{C}[14,15]$. Thereafter, quenching and tempering are applied. It is also considered that the direction of the plates has no influence on the distortion. To verify this hypothesis, measurements of the residual stresses were conducted in both the longitudinal and transversal directions, and the results were compared. The manufacturing process is presented in Fig. 1.

\subsection{Layer removal method using an innovative instrumented clamping system for residual stresses and part distortion determination}

\subsubsection{Principle of layer removal method}

The layer removal method provides information about the distribution of residual stress at all plate thicknesses. These stresses act in the direction of the curvature of the deformed plate after each removed layer [16]. As defined by Hospers and Vogelesang [17], a layer with thickness $\Delta t$ is removed from a plate with thickness $t_{i-1}$ and radius of curvature $r_{i-1}$. After removing this layer, a new plate thickness $t_{i}$ and curvature radius $r_{i}$ are obtained. The geometric parameters of this method are shown in Fig. 2.

An analytical method was used to calculate the average stress, $\sigma_{Y j}$, in the thickness of the removed layer, which is given by Eq. (1) [17].

$$
\begin{aligned}
\sigma_{Y Y i}= & \left\{\left[E / 12\left(1-\nu^{2}\right)\right]\left(t_{i}^{3} / r_{i}-t_{i-1}^{3} / r_{i-1}\right)-0.5 \Delta t_{i} \sum_{j=1}^{i-1} \sigma_{Y j} \Delta t_{i}\right\} \\
& /\left[0.5 \Delta t_{i}\left(t_{i}+\Delta t_{i} / 2\right)\right]
\end{aligned}
$$

$E$ is the Young modulus ( $197 \mathrm{GPa}$ at $20{ }^{\circ} \mathrm{C}$ ), $\nu$ is the Poisson ratio (0.3), and $\sigma_{Y Y i}$ is the residual stress averaged in each layer in the $Y$ direction.

The use of the layer removal method has two main advantages. First, it allows to the residual stress distribution in thick components to be obtained easily. Secondly, it enables the residual stresses to be correlated with part distortion, which can also be used to validate the distortion model.

The layers can be removed by machining processes, including conventional milling, based on the assumption that these processes do not induce additional residual stresses, so they do not contribute to part distortion. According to RichterTrummer et al. [8], high-speed milling using cutting tools has a low influence on part distortion. This hypothesis is based on a very low plastic strain and negligible thermal effect due to milling when the tool rotation speed and feed are high. Yang et al. [18] and Cerutti et al. [9] also assumed that the main factor affecting part distortion is the initial residual stresses (before machining) and that those induced during milling are of second order. To validate these hypotheses, a comparison was conducted between part distortion before and after removing layers by wire electrical discharge machining (EDM) [19]. EDM generates very weak residual stresses due to the thermal effect, but it does not induce contact stresses on the machined surfaces [20-22].

\subsubsection{Instrumented clamping system and distortion measurement strategy}

Figure 3 shows the instrumented clamping device, which is composed of two symmetric fastening parts, integrating three Kistler 9102A quartz load washer sensors. The sensitivity of these sensors has been investigated and calibrated. It is equal to $-4.3 \mathrm{pC} / \mathrm{N}$ for each load washer (references $1 \mathrm{R}, 1 \mathrm{~L}, 2 \mathrm{R}$, $2 \mathrm{~L}, 3 \mathrm{R}$, and $3 \mathrm{~L}$ ). The maximum measurement uncertainty for all load washers is $0.54 \%$. The transmission of axial forces in clamping is as follows. A screw (DIN912) supports the clamping forces, and the mechanical response is adjusted 


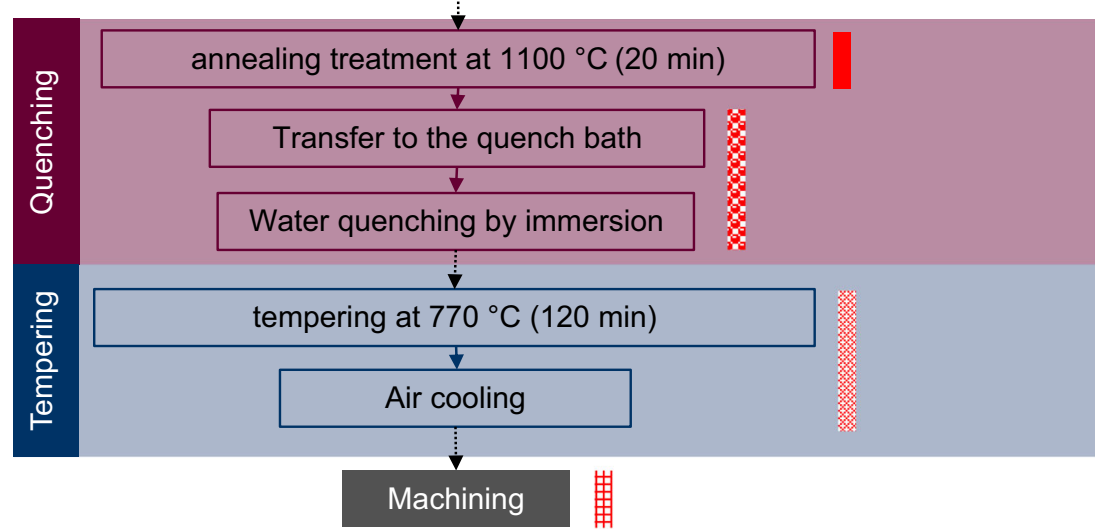

Residual stresses resulting from the rolling process are eliminated Residual stresses generated

Residual stresses relaxed

团 Residual stresses redistributed

automatically on the load washer through both a self-locking nut (DIN982) and spherical washer (DIN6319). The spherical washers are used to ensure that the clamping forces are perpendicular to the load washers.

A 3-component Kistler 9255B dynamometer was used to measure forces during machining in three directions. The position of the spindle axis is also determined in real time through the analogic outputs of the computer numerical control (CNC) machine (DMG DMC-65V 3 axis - vertical machining center). The acquisition devices are all triggered at the same time when the spindle is near the workpiece, and a reset was applied between each path. These precautions were applied to prevent force signal drift.

Ten samples were prepared to achieve two shoulders that are in contact with the screws, as shown in Fig. 3. This was done to (i) minimize the sequence effect (i.e., distortions after unclamping and its effect in the real depth of cut on the following removed layer), which is generated if only one sample is used, and (ii) ensure uniform thickness in all sample positions after each test. As illustrated in Table 1, after removing all layers corresponding to each experiment, the thickness of each sample $t_{i}$ (Fig. 2) should be constant (i.e., $t_{i}=h \rightarrow$ sample without shoulders).

All samples used for the layer removal experiments had the same width and length which are equal to $99 \mathrm{~mm}$ and $200 \mathrm{~mm}$, respectively. Cutting fluid (oil/water emulsion) was applied during all machining tests. The cutting depth $a_{P}$ was fixed to $1 \mathrm{~mm}$ (thickness $\Delta t$ (Fig. 2) was considered equal to the depth of cut $a_{P}$ ), the feed per tooth $f_{Z}$ was equal to $0.15 \mathrm{~mm} / \mathrm{tooth} /$ rev, and the cutting speed $V_{C}$ applied was $130 \mathrm{~m} / \mathrm{min}$.

The maximum number of removed layers corresponds to test $\mathrm{J}$. Therefore, this test was repeated ( $\mathrm{J}$ ') to verify its repeatability. Shoulder preparation caused slight distortions of samples (maximum deflection equal to $0.045 \mathrm{~mm}$ ). An initial clamping force of $10 \pm 0.2 \mathrm{kN} / \mathrm{screw}$ was chosen to flatten the samples before layer removal. A face milling tool holder equipped with octagonal inserts was used for the tests (reference ISCAR HOF D063-04-22-R07). The inserts were
Fig. 2 Geometric parameters of layer removal method

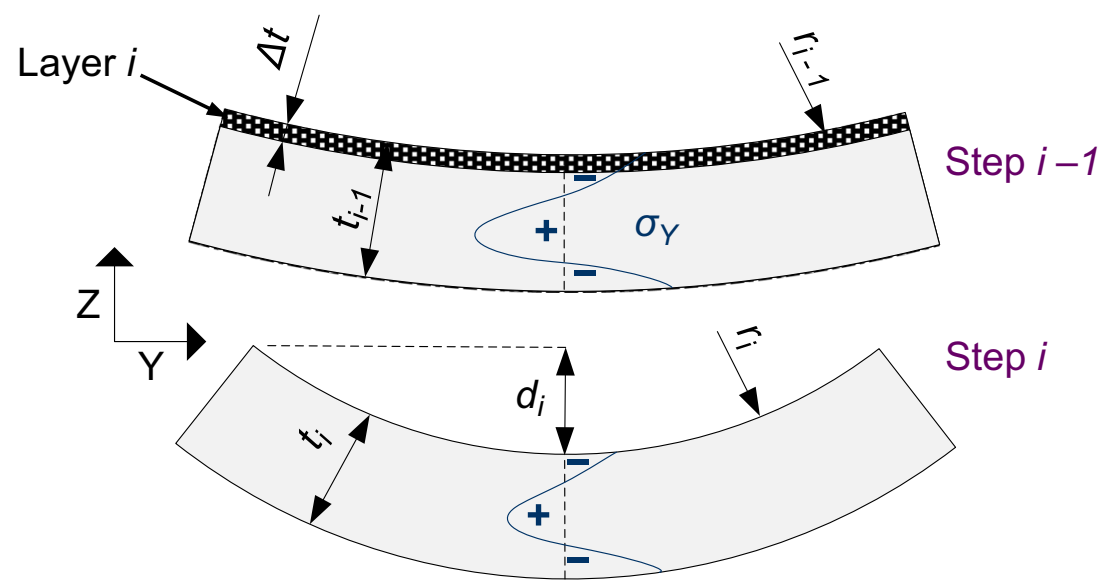


Fig. 3 Experimental clamping system integrating load washer sensors 1R, 1L, 2R, 2L, 3R, and $3 \mathrm{~L}$ ( $\mathrm{L}$ - left, $\mathrm{R}$ - right)

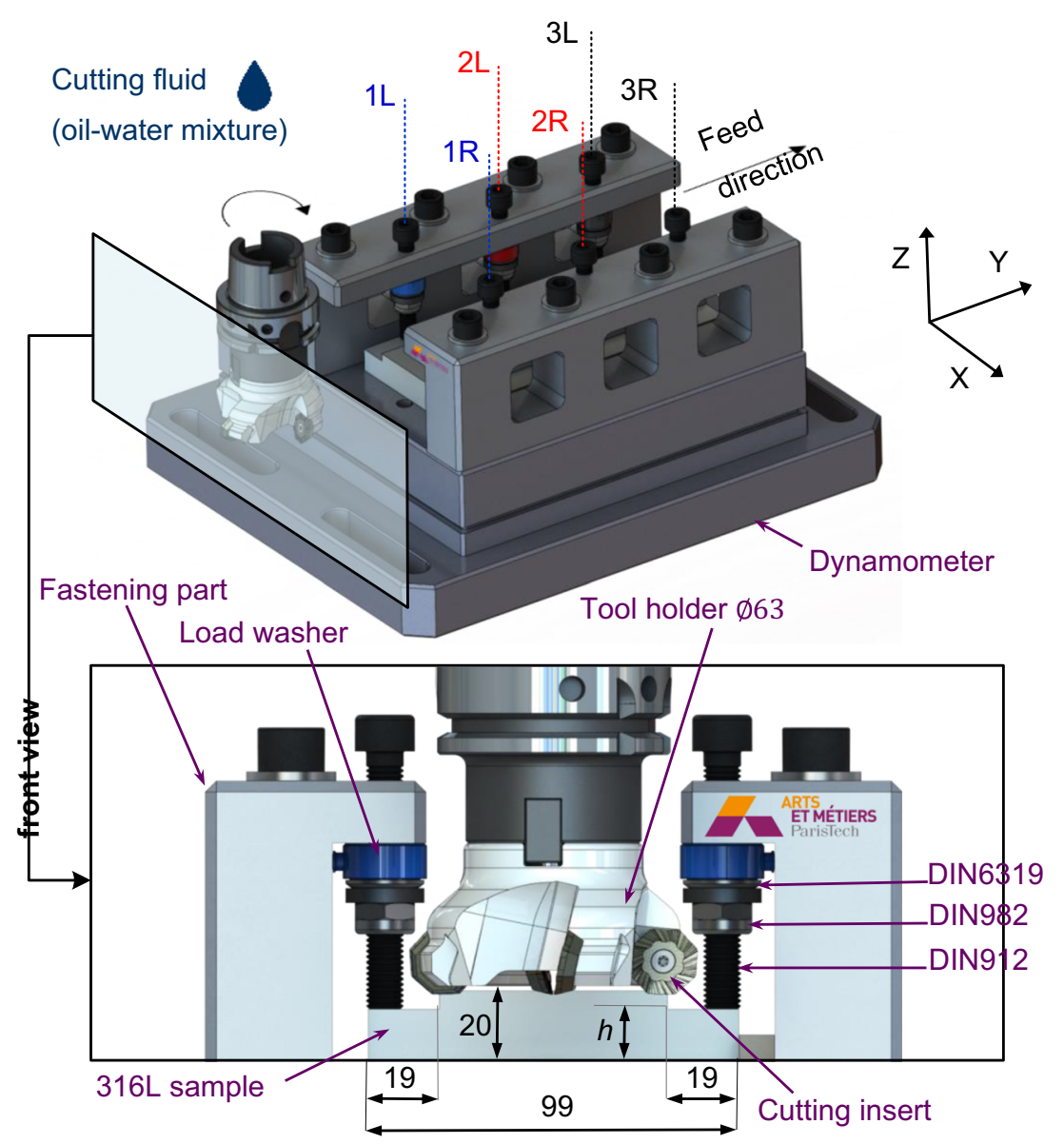

composed of a tungsten carbide substrate with a TiAlN PVD coating (reference ISCAR OFCT 07T3 AETN-16 IC908).

After unclamping, a coordinate-measuring machine (CMM) was used to determine the $(X, Y, Z)$ coordinates of 1300 points on the top surfaces of the deformed samples to measure the global part distortion. The measuring points were spaced $3 \mathrm{~mm}$ in both the $X$ and $Y$ directions. The maximum permissible error (MPE) for length measurement was set to $2.1 \mu \mathrm{m}$.

\subsection{Residual stress determination by neutron diffraction technique}

The objective of the residual stress measurements by neutron diffraction is to validate the methodology used in the previous section, i.e., determining the residual stresses by the layer removal method with an innovative clamping system. A STRESS-SPEC diffractometer available at FRM II of the
Technical University of Munich (Germany) was used. This diffractometer is optimized for strain [23] and texture measurements [24]. The sample dimensions used for the neutron diffraction experiment were $150 \mathrm{~mm} \times 150 \mathrm{~mm} \times 20 \mathrm{~mm}$. The experimental set-up is shown in Fig. 4. The three residual stress components $\left(\sigma_{X}, \sigma_{Y}\right.$, and $\left.\sigma_{Z}\right)$ were measured, and the position of each sample was modified depending on the desired direction of stress. The residual stresses in a flat plate of uniform thickness are assumed to be biaxial when they are not near the edges [16]. Therefore, in this study, it is assumed that the residual stresses are in the $X$ and $Y$ directions, as shown in Fig. 4. Based on this hypothesis, the scattering reference angle $2 \theta_{0}$ was determined when $\sigma_{Z}$ is zero. Its value was set at $101.159 \pm 0.02^{\circ}$. Then, $\sigma_{X}$ and $\sigma_{Y}$ were calculated using the above assumptions for the neutron diffraction technique [25, 26]. The take-off angle of the silicon $\mathrm{Si}$ (400) monochromator was set to $2 \theta_{M}=75.90^{\circ}$ so that a wavelength of approximately $1.67 \AA$ was obtained for the residual stress measurements. At
Table 1 Geometric parameters for each sample

\begin{tabular}{lllllllllll}
\hline Test & A & B & C & D & E & F & G & H & I & J, J', \\
\hline Shoulder thickness $h$ (mm) (Fig. 3) & 19 & 18 & 17 & 16 & 15 & 14 & 13 & 12 & 11 & 10 \\
Number of removed layers $i$ & 1 & 2 & 3 & 4 & 5 & 6 & 7 & 8 & 9 & 10 \\
\hline
\end{tabular}


Fig. 4 Neutron diffraction setup using STRESS-SPEC diffractometer at FRM II

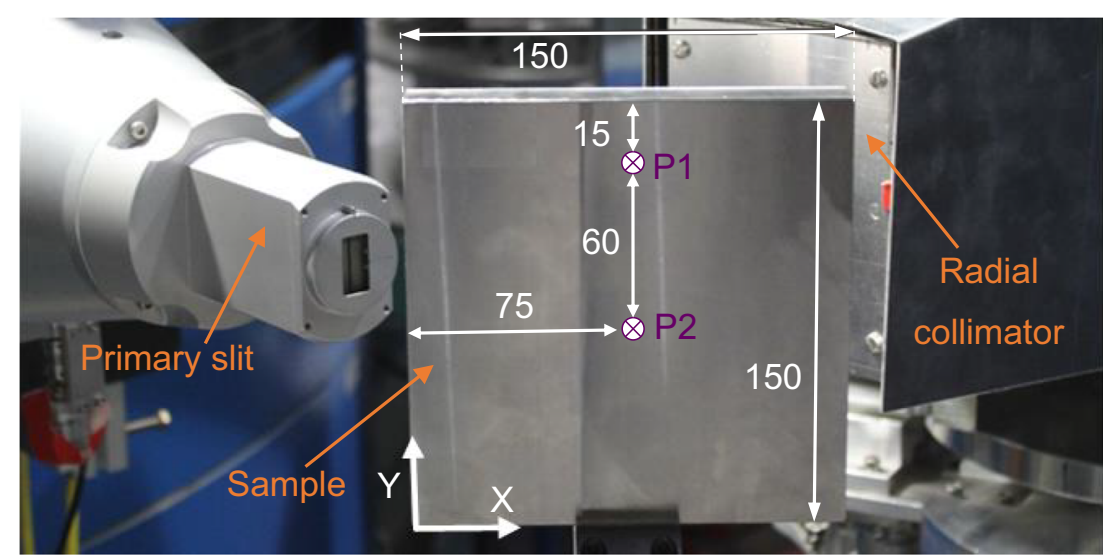

the primary beam, a slit was used to create a $1 \mathrm{~mm} \times 6 \mathrm{~mm}$ (width $\times$ height) window, and at the diffracted beam, a 2-mm (full width at half maximum) radial collimator was used, thus defining a gauge volume of $1 \times 6 \times 2 \mathrm{~mm}^{3}$, which enables a 3 min measurement time at each point for the required spatial resolution. The diffraction data were collected with a $3 \mathrm{He}$ PSD detector with $1 \mathrm{~mm}$ resolution and $250 \mathrm{~mm} \times 250 \mathrm{~mm}$ dimensions [27]. In this study, the residual stress measurements of two profiles in the depth direction along the plate cross-section are presented. The position of each of them is shown in Fig. 4 by P1 and P2.

\section{Model for part distortion prediction}

A model that predicts part distortion induced by machining was developed and simulated using SYSWELD software. Ten simulations were performed by applying the same methodology and experimental conditions. The model considers both the sequence effect after each cutting step and the clamping/ unclamping conditions. This model considers the deformed geometry at a previous machining stage and then uses it as input data for the current one. The numbers of layers to be removed in each simulation are listed in Table 1.

Figure 5 shows the mesh and boundary conditions. A pressure was applied to each screw in the $Z$ direction, corresponding to a force of $10 \mathrm{kN} / \mathrm{screw}$. The nodes of $2 \mathrm{D}$ elements are blocked along the $X$ and $Y$ directions, and the contact between the screws and the part is frictionless. Moreover, a contact without friction is applied between the dynamometer and the part. To reduce the calculation time, the dynamometer is defined by a set of nodes. The last step of each simulation (unclamping stage) consists of removing the clamping pressures. After studying mesh types and sizes, the model was defined using hexahedral elements (with 8 nodes) except for the refined elements under the screw positions. The element width varies between 2 and $5.6 \mathrm{~mm}$, and the length and depth are fixed to 5 and $0.25 \mathrm{~mm}$, respectively. The boundary conditions and mesh of the sample of the J test (see Table 1) after the preparation stage are presented in Fig. 5. The N1, N2, and
Fig. 5 Mesh and boundary conditions (the sample of the $\mathrm{J}$ test after preparation stage)

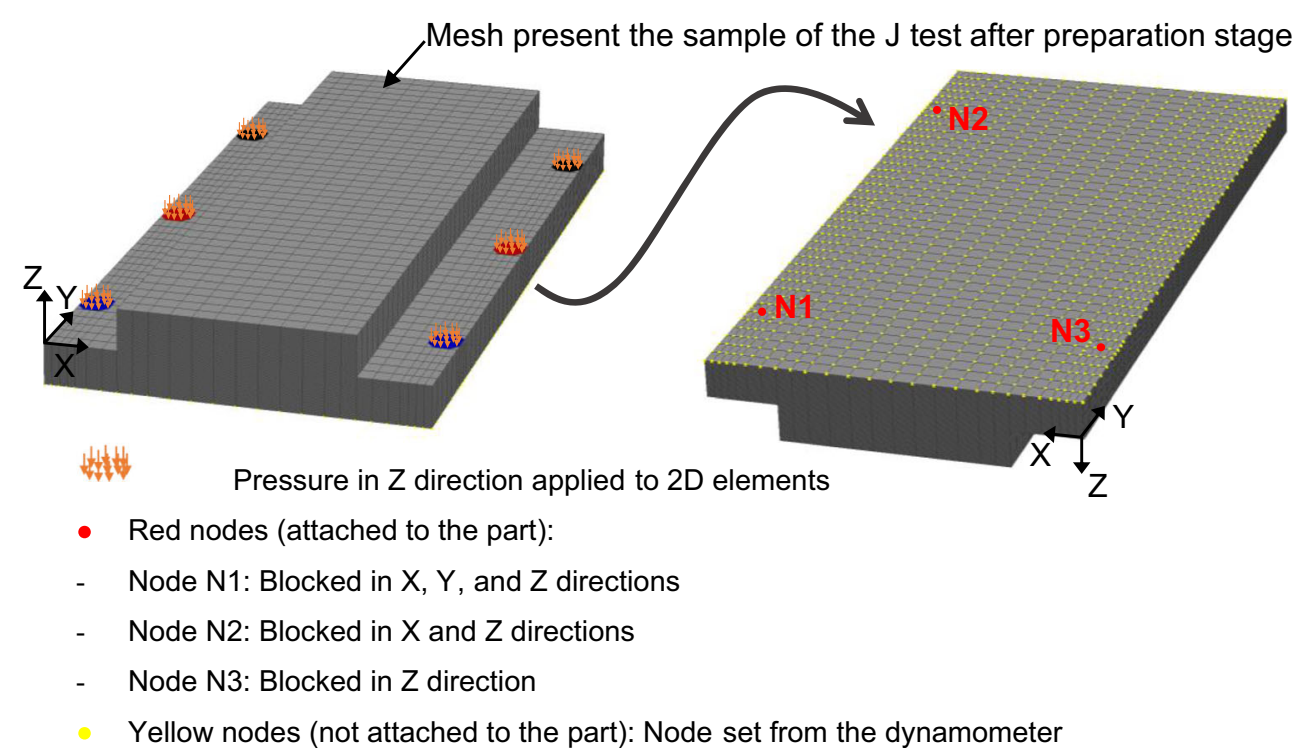


Fig. 6 Experimental and predicted residual stress distributions in the part induced by heat treatments (ND: neutron diffraction, LR: layer removal, NUM: numerical calculations)

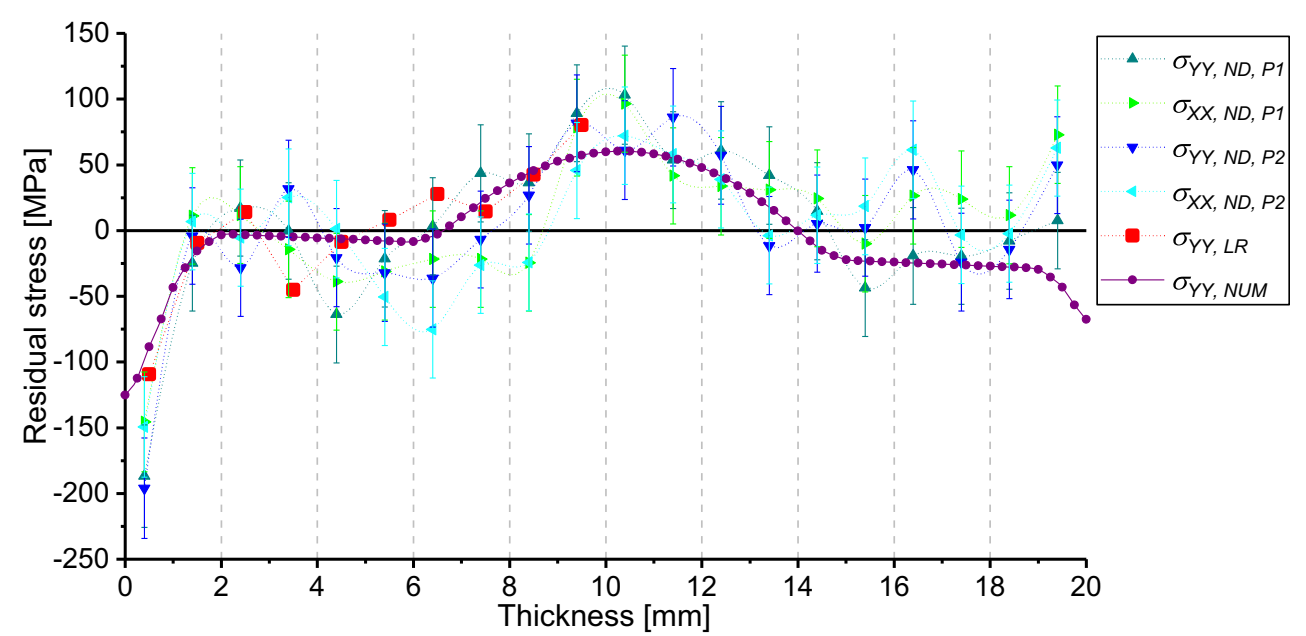

$\mathrm{N} 3$ nodes are blocked, as shown in Fig. 5, to fasten the part while allowing its deformation (i.e., to ensure a statically determinate part). The von Mises plasticity criterion with isotropic hardening was used. Thermomechanical data were provided by the Framatome company. The residual stress distribution was integrated in this distortion model to represent its initial mechanical state.

\section{Results and discussion}

\subsection{Residual stress}

The residual stress measurements by neutron diffraction are shown in Fig. 6 as $\sigma_{Y Y, N D, P_{1,2}}$ and $\sigma_{X X, N D, P_{1,2}}$ depending on both the directions of stresses and positions of the measurements $\mathrm{P} 1$ or P2 (Fig. 4). Wawszczak et al. [15] found that, after rolling, the residual stresses in a 316L plate in the rolling and transversal directions are not identical. However, the neutron diffraction results show that the residual stresses follow the same distribution in both the $X$ and $Y$ directions. Thus, residual stresses generated from rolling are eliminated during heat treatment, validating the previous hypothesis. The neutron diffraction measurements also show uniform residual stress distributions in both positions P1 and P2. The residual stress distributions obtained by the layer removal method are presented in Fig. 6 as $\sigma_{Y Y, L R}$. They are well correlated with those measured by neutron diffraction.

According to Fig. 6, the residual stresses measured by neutron diffraction are not symmetrical along the thickness. In fact, compressive stresses exist until approximately $2 \mathrm{~mm}$ below the lower surface, tensile stresses exist between 7 and $14 \mathrm{~mm}$ below this surface, and the remaining stresses are almost zero. The curve of $\sigma_{Y Y, \text { NUM }}$ presented in Fig. 6 shows the numerical residual stresses in the $Y$ direction throughout the thickness. These data define the initial residual stress distributions in the samples, which serve as input data for the distortion model.

\subsection{Part distortion}

Figure 7 shows the $Z$ coordinates of the points on the machined surface measured by CMM in the midline of each sample after
Fig. 7 Distortion points per sample in the midline

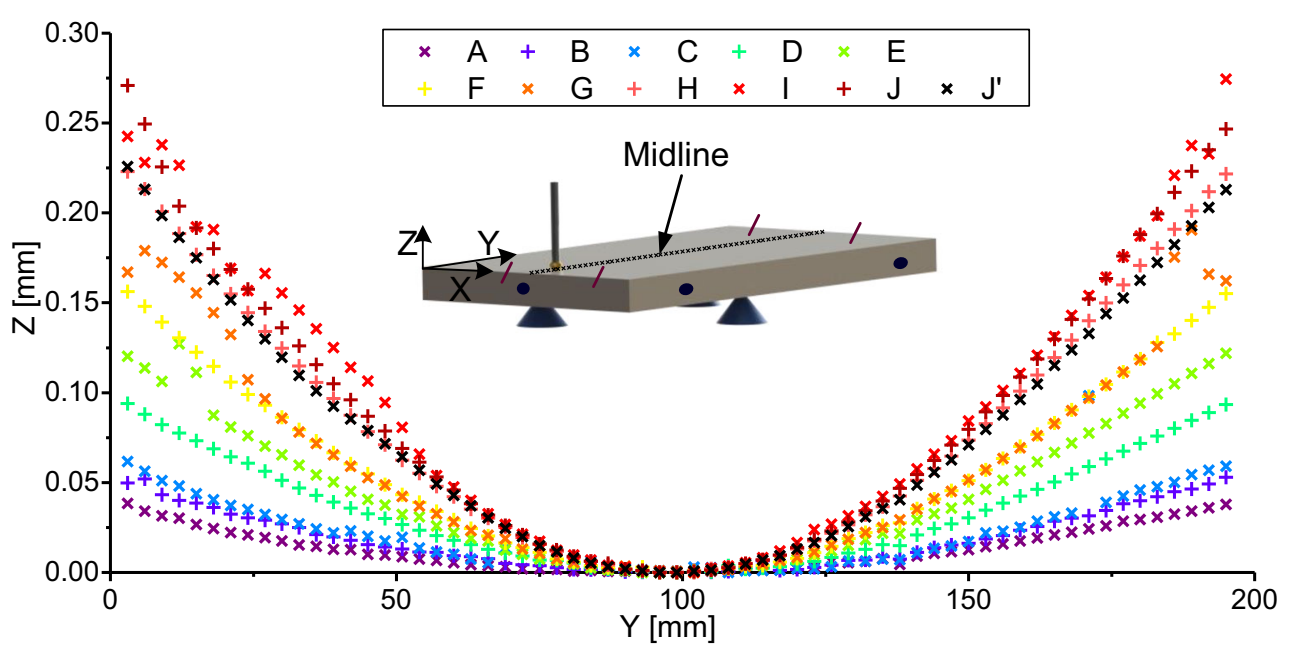




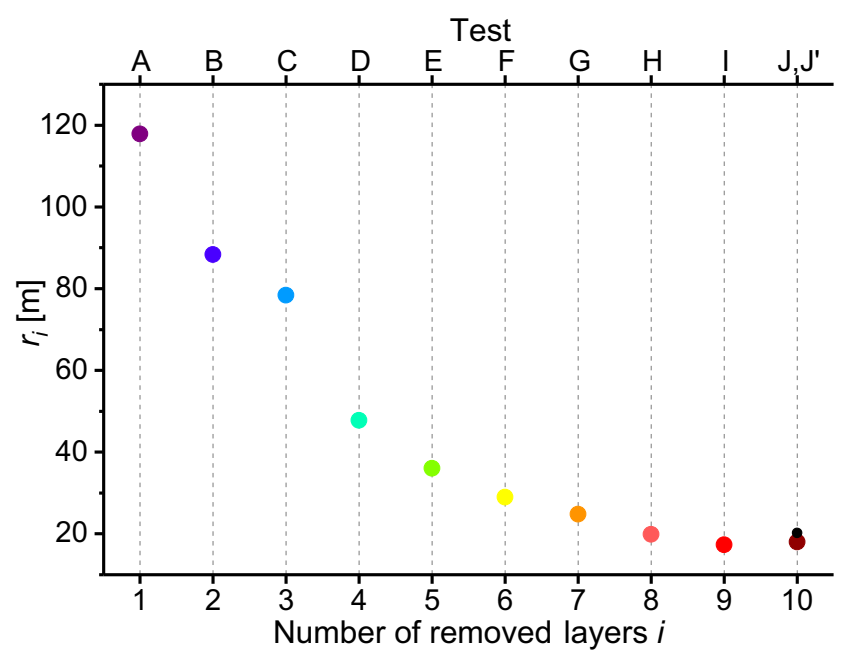

Fig. 8 Radius of curvature $r_{i}$ (Fig. 2) of machined samples

milling. As can be seen in this figure, part distortion is relatively high, reaching approximately $0.30 \mathrm{~mm}$, and it increases with the number of removed layers. Actually, the maximum deflection $d_{i}$ (see Fig. 2) between tests A and $\mathrm{J}$ increases by $86 \%$.

A nonlinear curve fitting was applied to determine the radius of curvature of each sample after the distortion. Then, the residual stresses were determined by applying the layer removal method, as described in Section 2.1. The results of the radii of curvature $r_{i}$ (see Fig. 2) as a function of the number of layers being removed are presented in Fig. 8.

The maximum absolute error of this curve fitting is equal to $0.8 \mathrm{~mm}$, which is considered negligible compared to the determined radii. The distortion variation is greater for the removed layers located near the surface, when compared with those layers in the middle of the sample thickness. For example, the variation of the radius between tests A and B and I and $\mathrm{J}$ is equal to $25 \%$ and $5 \%$, respectively.

The maximum deflections $d_{i}$ (parameter representing the part distortion) obtained experimentally (high-speed milling (HSM) and EDM) and by numerical simulations are shown in Fig. 9.

As seen in Fig. 9, the evolution of the maximum deflections induced by HSM and EDM is almost equal. This means that the influence of the residual stresses introduced by milling on part distortion can be neglected for the specific cutting conditions used in these tests. Moreover, the difference between the maximum numerical and experimental deflections is relatively small, increasing progressively with the thickness of the removed layer. This may be due to the prediction in the $\mathrm{FE}$ model or the residual stresses introduced by machining. According to Fig. 9, the maximum deflection rapidly increased up to approximately 5 removed layers and the increase slowed down thereafter.

The unbalanced rate of the residual stress after material removal can represent the level of distortion. This rate can be determined from the integral of the residual stress through the thickness (before unclamping). Figure 10a shows the numerical residual stress $\sigma_{Y Y, N U M}$ area in the plate center through the thickness as a function of the number of removed layers.

Figure 10b shows the residual stress area values through the thickness for each test (i.e., the residual stress integral for each distribution) and the variation of the maximum deflection calculated from its derivative. This figure reveals that both evolutions have the same pattern. This explains the reason behind the great distortion variation when the removed layers are located near the surface and the low distortion variation when the removed layers are near the center.

Figure 11 shows the numerical residual stress $\sigma_{Y Y, N U M}$ distribution in the plate center through the thickness as a function of the number of removed layers (after unclamping). This figure shows that the residual stress distribution is in equilibrium after unclamping. According to these results, the residual stress increases by $40 \%$ in the lower surface when the layers are successively removed. However, the compression stress in the material removal face decreases to a threshold. The residual stress in this case decreases by $87 \%$ up to a threshold of 5 layers of material removed (corresponding to $5 \mathrm{~mm}$, which is onequarter of the initial thickness). However, for more than $5 \mathrm{~mm}$ to the middle of the thickness, the residual stress in the material removal face increases by $111 \%$. These observations further demonstrate the curvature shape and distortion evolution after machining. Based on these results, the distortion after machining can be minimized when the material removal is symmetrical along the thickness (material machined from both faces).
Fig. 9 Maximum deflections $d_{i}$ obtained from the experiments and simulations after machining

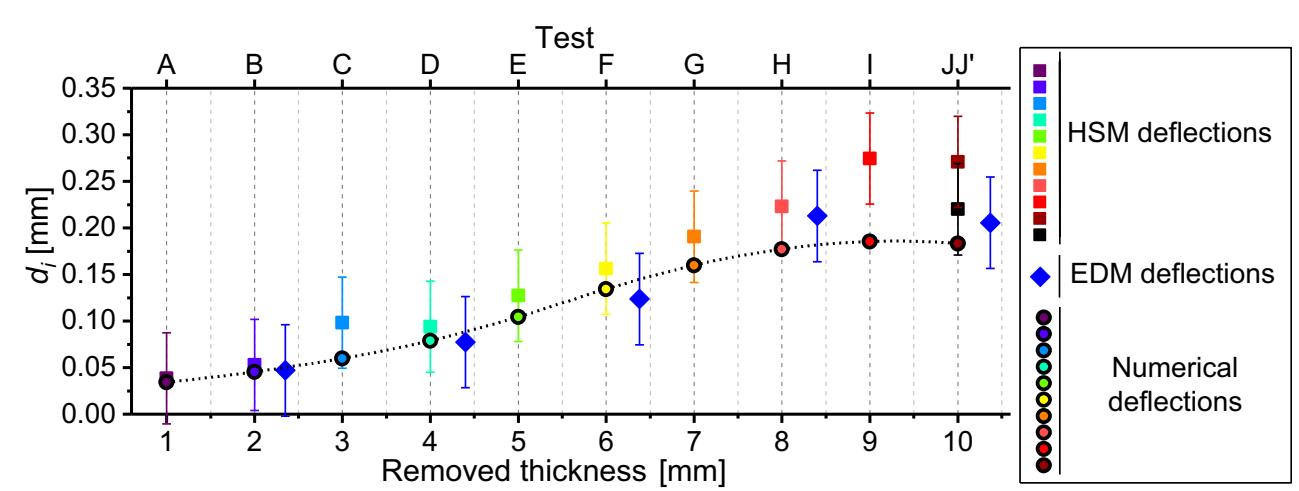


Fig. 10 a Numerical residual stress $\sigma_{Y Y, N U M}$ area in the plate center through the thickness as a function of the number of removed layers. b Comparison between evolution of residual stress area before unclamping and maximum deflection after unclamping (a)

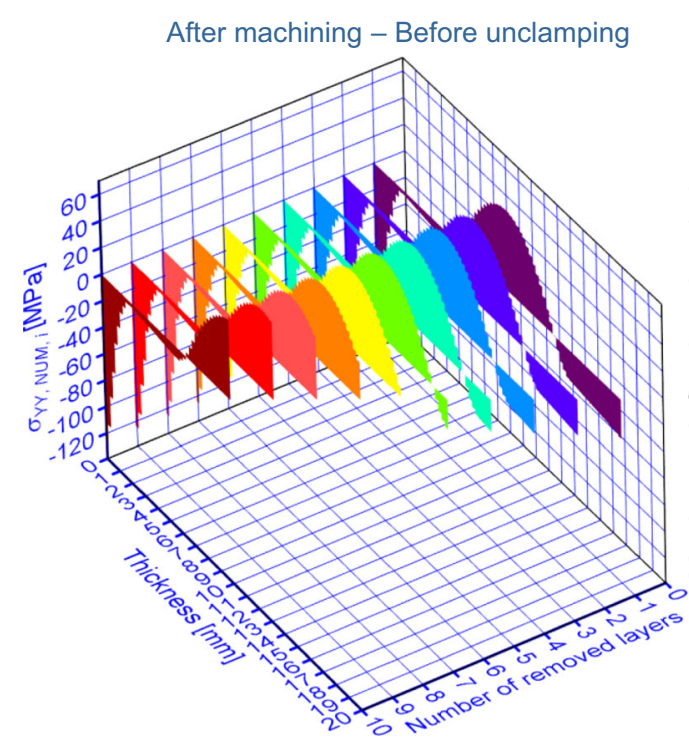

Figure 12 highlights the effect of the clamping system on the stress distributions in the $Y$ and $Z$ directions before and after unclamping for the $J$ test sample. Figure $12 \mathrm{a}$ and $\mathrm{c}$ show the distribution of stresses before unclamping when the sample is completely machined. It is clear here that the external stresses generated by the clamping can influence the final residual stress distribution in the plate. In this case, stresses are not balanced, which is contrary to the second case (after unclamping), where residual stresses were in equilibrium (Fig. $12 \mathrm{~b}, \mathrm{~d})$. As can be seen in this second case, the distribution of residual stresses throughout the thickness is heterogeneous in the area where the clamping was applied. In the first case (before unclamping), Fig. 12a shows a partial equilibrium of residual stresses, and they are distributed in a non-uniform manner throughout the thickness. This partial equilibrium is present in the zones with weak stress from clamping. The primary distortion at this phase is the image of this partial equilibrium. This initial distortion induced after each layer is removed affects the global distortion after unclamping (Fig. 12b). As a result, the partial equilibrium of residual stresses affects the global distortion and explains the influence of the clamping on machining distortion. The sequence effect applied in all simulations is significant because it considers the primary distortions generated after each layer removal.

\subsection{Clamping forces}

Only the overall clamping forces due to distortion are presented in this article without considering the toolworkpiece interaction. As shown in Fig. 13, total clamping force $F_{C, \text { Total }}^{i}$ of the six screws (Fig. 3) is
Fig. 11 Numerical residual stress $\sigma_{Y Y, N U M}$ distribution in the plate center through the thickness as a function of the number of removed layers

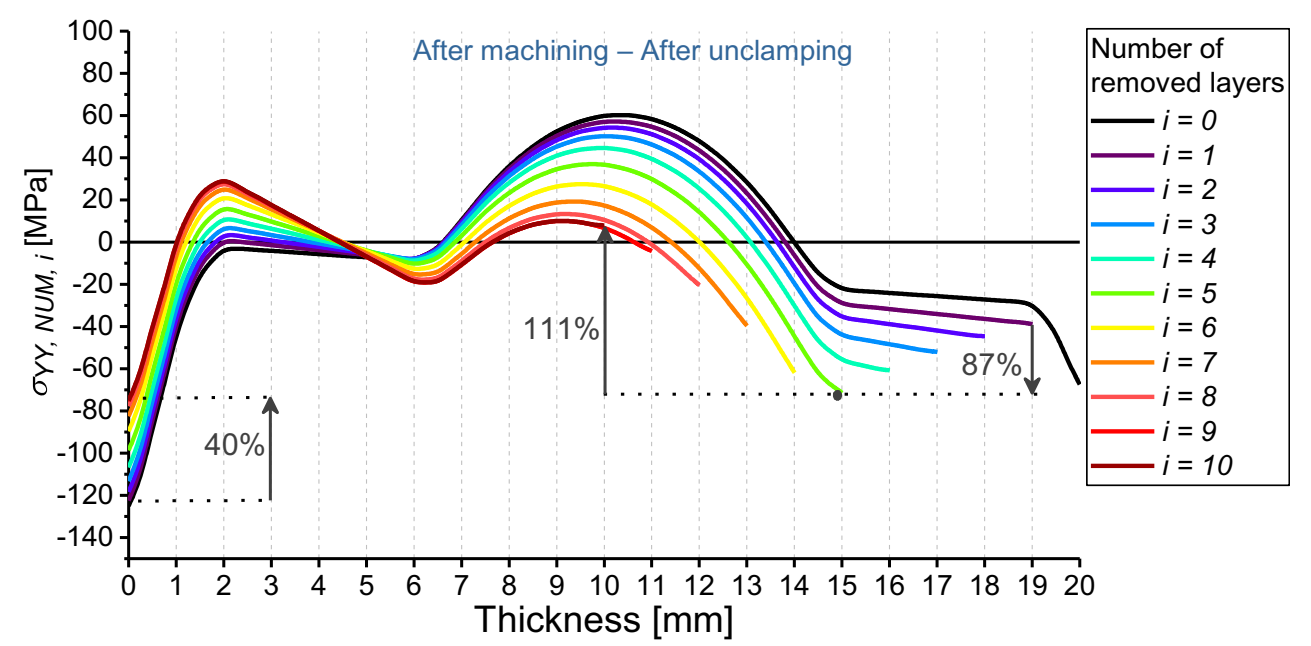


Fig. 12 Numerical residual stress distributions (a) $\sigma_{Y Y, N U M}$ after machining and before unclamping, (b) $\sigma_{Y Y, N U M}$ after (c) $\sigma_{Z Z, N U M}$ after machining and before unclamping, and (d) $\sigma_{Z Z}$ $N U M$ after machining and after unclamping machining and after unclamping,

\section{Last two stages (before and after unclamping) for $\mathrm{J}$ test simulation}

Display scale multiplied by 100

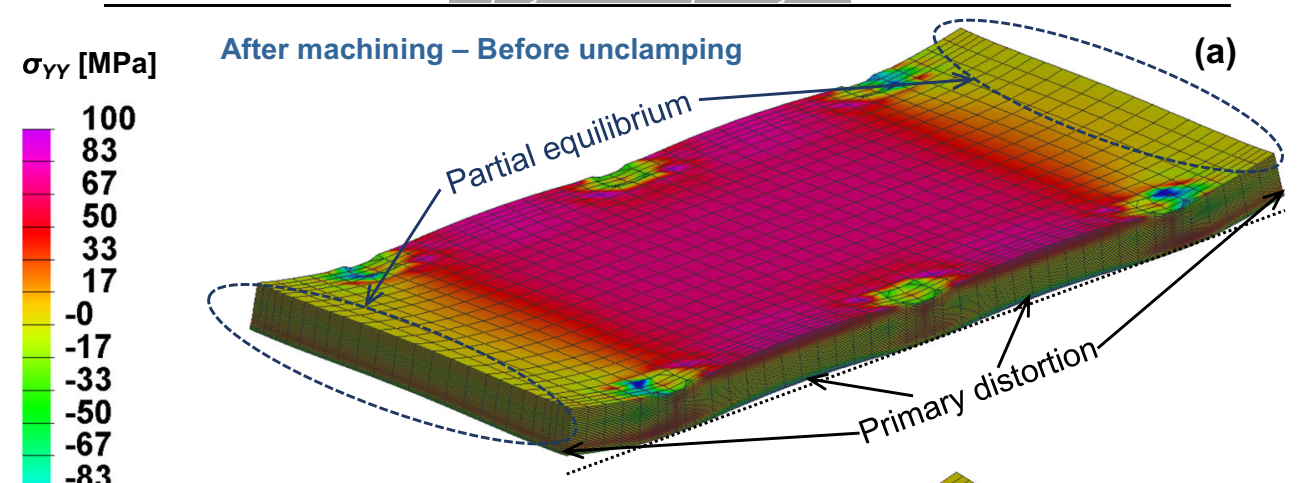

(b)

$-117$

$-133$

$-150$
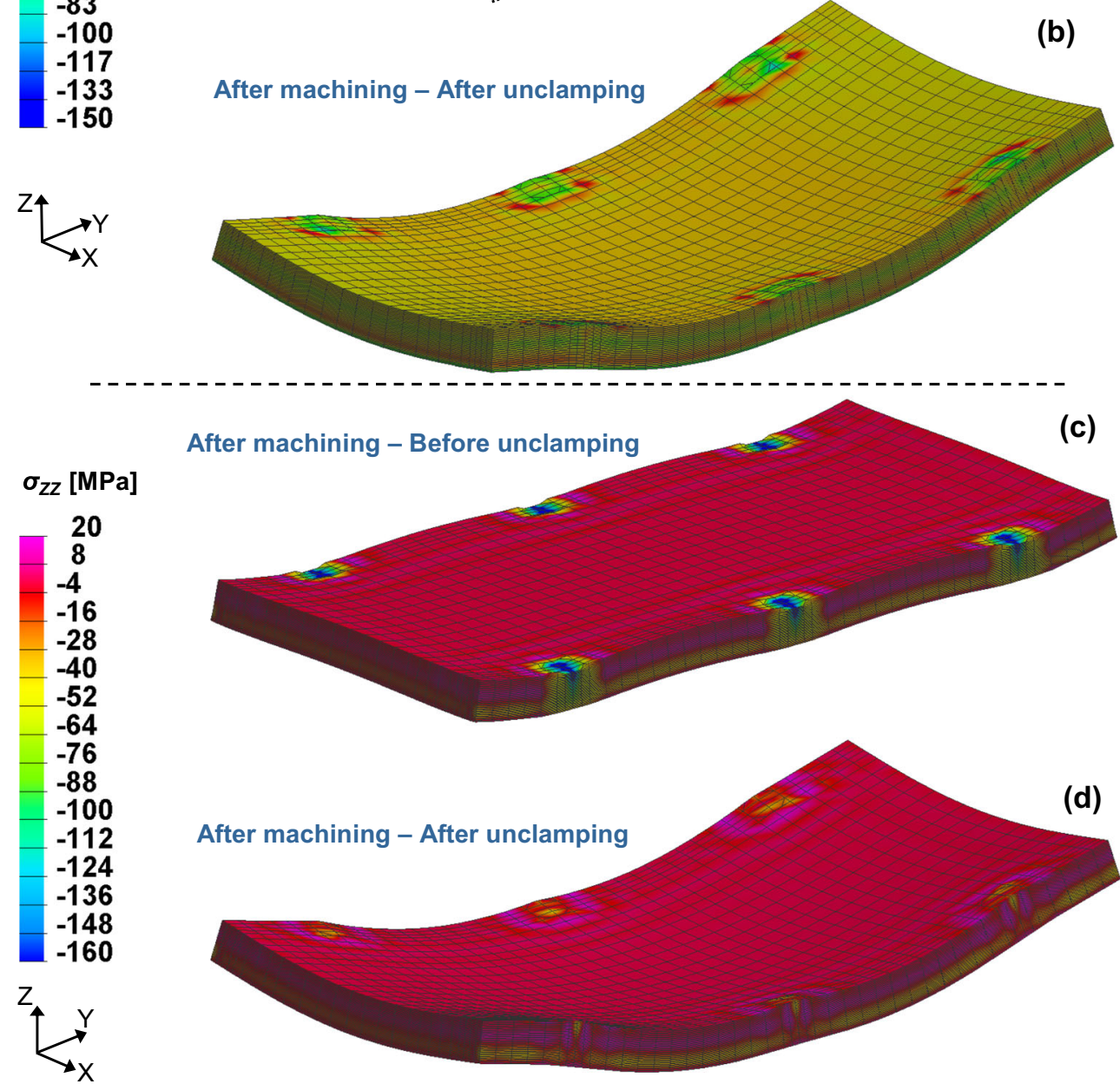

accumulated after each removed layer. This total clamping force is calculated using Eq. (2).

$$
\begin{aligned}
& F_{C, T o t a l}^{i} \\
= & F_{C, 1 \mathrm{R}}^{i}+F_{C, 1 \mathrm{~L}}^{i}+F_{C, 2 \mathrm{R}}^{i}+F_{C, 2 \mathrm{~L}}^{i}+F_{C, 3 \mathrm{R}}^{i}+F_{C, 3 \mathrm{~L}}^{i}, \\
& i=\{0 ; 10\}: \text { number of removed layers, }
\end{aligned}
$$$$
F_{C, \text { Total }}=F_{C, \text { Total }}^{0}+\sum_{i=1}^{10} \Delta F_{C, \text { Total }}^{i}
$$

(2) $F_{C, \text { Total }}^{0}$ : initial clamping force before machining,

where

$$
F_{C, \text { Total }}^{0}=6 \times(10 \pm 0.2) \mathrm{kN}
$$

$$
F_{C, \text { Total }}^{i}=F_{C, \text { Total }}^{i+1}-F_{C, \text { Total }}^{i} \text {, }
$$




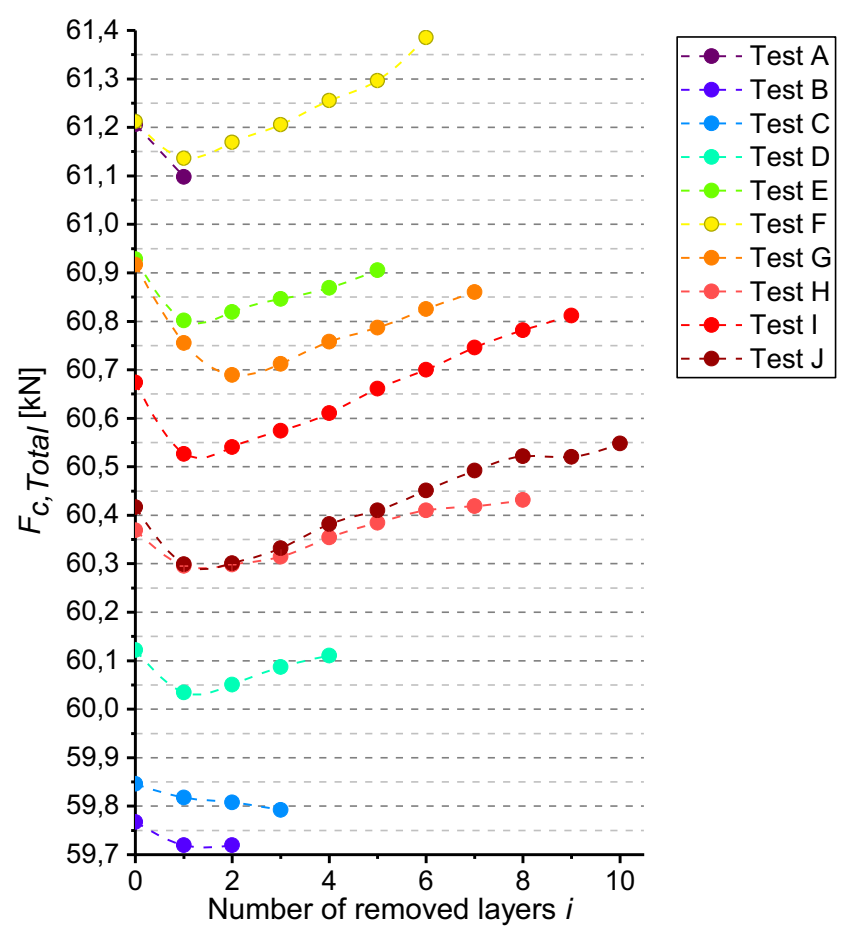

Fig. 13 Total clamping force after each removed layer (experimental results)

The maximum uncertainty of measurement does not exceed $2.3 \mathrm{~N}$. Consequently, the error bars are small enough to be visible. However, the uncertainty of measurement is not related only about load washers; many complex phenomena not studied can intervene such as the dynamic effects and the actual distribution of residual stresses and their influence on the distortion, thus on the clamping forces.

To check that the initial clamping force incertitude does not affect the magnitude of the clamping during machining, two simulations were conducted for the $\mathrm{J}$ test sample (Sim_1 $\mathrm{J}$ and Sim_2 J) with different initial clamping forces $(59.967 \mathrm{kN}$ and $60.392 \mathrm{kN}$, respectively).
According to Fig. 13, the evolution of the total clamping force as a function of the number of removed layers follows the same trend for all tests. Furthermore, as shown in Fig. 14, the numerical results of the clamping force for test $\mathrm{J}$ show good agreement with the measurement results (only $\mathrm{J}$ test simulation result is presented because the number of layers removed from the sample used for this test is maximal). After all layers were removed from the $\mathrm{J}$ test sample, the total clamping force increased $129 \mathrm{~N}$ in the simulation and $131 \mathrm{~N}$ experimentally, which is a difference of only $1.5 \%$. According to Fig. 14, both simulations (Sim_1 J and Sim $\_2$ J) for the J test sample showed that the uncertainty due to the initial clamping force has no effect on the evolution of the magnitude of clamping. Both numerical simulations and experimental tests revealed that the maximum clamping force caused by machining distortion is much lower than the initial clamping force $(10 \mathrm{kN} / \mathrm{screw})$. Therefore, this initial force ensures the flattening of the samples after slight deformations due to preparation.

\section{Conclusions}

The distribution of the residual stresses in a part before machining is essential for predicting part distortion after machining. In this study, residual stresses were induced by heat treatment of AISI 316L stainless steel plates and were determined by both destructive and nondestructive methods. The results highlight that the layer removal method has sufficient accuracy to determine the residual stress distribution in a plate.

The real residual stress measurements served to validate the initial distribution of stresses in the FE model before machining. It was supposed that the residual stresses produced by machining are of second order, and this assumption was confirmed by comparing the distortions observed using the HSM and EDM processes.
Fig. 14 Total clamping force after each removed layer (comparison between experimental and numerical results)

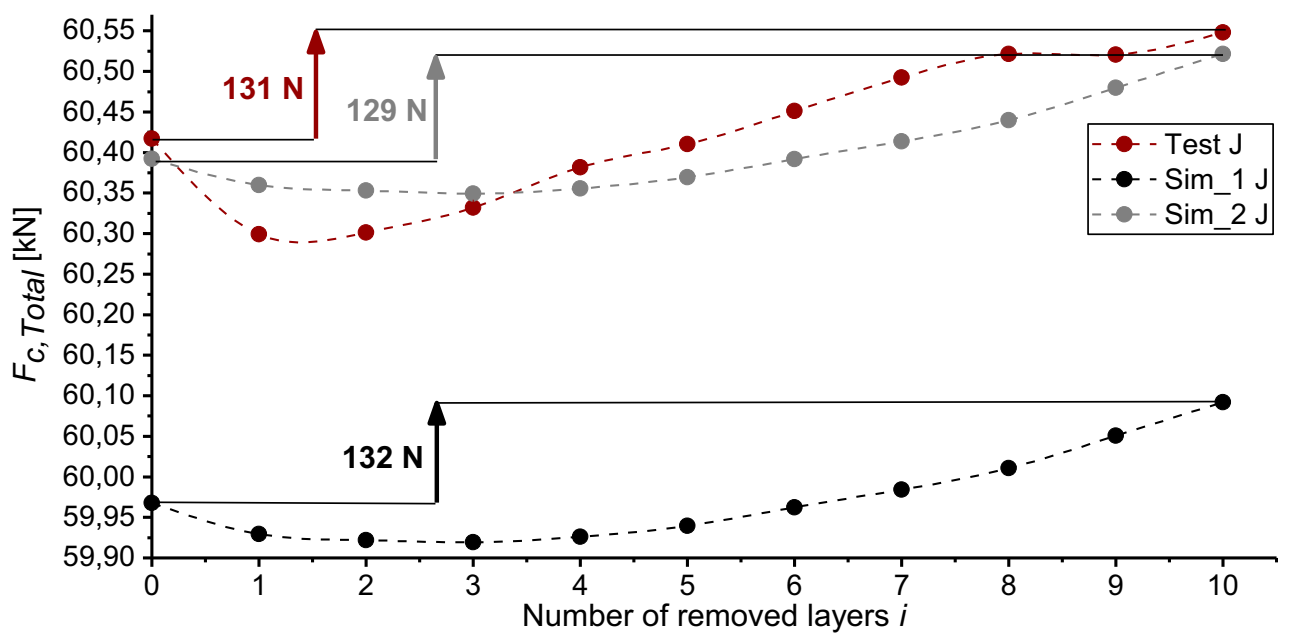


An innovative FE model for predicting part distortion and clamping forces was developed and validated. The residual stress was studied using the numerical model results to explain the curvature shape and distortion evolution after machining.

Due to the local residual stress gradient through the thickness after unclamping, this model confirms that clamping affects machining distortion.

The clamping force was controlled in real time using an instrumented clamping device designed especially for this study. The results show that the clamping force varies as a function of the material removal. However, the maximum value of this variation is very low compared with the initial clamping force.

Future work will focus on (i) the clamping reaction in different screws when the cutting tool is in contact with the workpiece, (ii) the influence of a variable clamping force after each cutting step on distortion, and (iii) expanding the distortion model with the residual stress induced by machining.

Funding information This research was financially supported by the Burgundy regional council of Bourgogne-Franche-Comte through the Regional Action Plan for Innovation, the European Union through the PO FEDER-FSE Bourgogne 2014/2020 programs, and FRAMATOME.

\section{Compliance with ethical standards}

Conflict of interest The authors declare that they have no conflict of interest.

\section{References}

1. Pra F, Tochon P, Mauget C, Fokkens J, Willemsen S (2008) Promising designs of compact heat exchangers for modular HTRs using the Brayton cycle. Nucl Eng Des 238(11):3160-3173

2. Xiuqing L, Le Pierres R, Dewson SJ (2006) Heat exchangers for the next generation of nuclear reactors. American Nuclear Society ANS, United States

3. Mannan MA, Sollie JP (1997) A force-controlled clamping element for intelligent fixturing. CIRP Ann 46(1):265-268

4. Boerma JR, Kals HJJ (1989) Fixture design with FIXES: the automatic selection of positioning, clamping and support features for prismatic parts. CIRP Ann 38(1):399-402

5. Raghu A, Melkote SN (2004) Analysis of the effects of fixture clamping sequence on part location errors. Int $\mathrm{J}$ Mach Tools Manuf 44(4):373-382

6. Wu NH, Chan KC (1996) A genetic algorithm based approach to optimal fixture configuration. Comput Ind Eng 31(3-4):919-924

7. Rai JK, Xirouchakis P (2008) Finite element method based machining simulation environment for analyzing part errors induced during milling of thin-walled components. Int J Mach Tools Manuf 48(6):629-643

8. Richter-Trummer V, Koch D, Witte A, dos Santos JF, de Castro PMST (2013) Methodology for prediction of distortion of workpieces manufactured by high speed machining based on an accurate through-the-thickness residual stress determination. Int J Adv Manuf Technol 68(9):2271-2281

9. Cerutti X, Mocellin K, Hassini S, Blaysat B, Duc E (2017) Methodology for aluminium part machining quality improvement considering mechanical properties and process conditions. CIRP J Manuf Sci Technol 18:18-38

10. Li B, Melkote SN (1999) Improved workpiece location accuracy through fixture layout optimization. Int J Mach Tools Manuf 39(6): $871-883$

11. Asante JN (2008) A combined contact elasticity and finite elementbased model for contact load and pressure distribution calculation in a frictional Workpiece-fixture system. Int J Adv Manuf Technol 39(5-6):578-588

12. Siebenaler SP, Melkote SN (2006) Prediction of workpiece deformation in a fixture system using the finite element method. Int $\mathrm{J}$ Mach Tools Manuf 46(1):51-58

13. Rai JK, Xirouchakis P (2009) FEM-based prediction of workpiece transient temperature distribution and deformations during milling. Int J Adv Manuf Technol 42(5-6):429-449

14. Committee AIH, Douthett J (1991) ASM handbook: heat treating. ASM International

15. Wawszczak R, Baczma A, Braham C, Berent K (2016) Evolution of microstructure and residual stress during annealing of austenitic and ferritic steels, Materials Characterization, $\mathrm{p} 14$

16. Totten GE (2002) Handbook of residual stress and deformation of steel. ASM International

17. Hospers F, Vogelesang LB (1975) Determination of residual stresses in aluminum-alloy sheet material. Exp Mech 15(3):107-110

18. Yang Y, Li M, Li KR (2014) Comparison and analysis of main effect elements of machining distortion for aluminum alloy and titanium alloy aircraft monolithic component. Int J Adv Manuf Technol 70(9-12):1803-1811

19. Laracine M, Bignon C, Boivin M, Lormand M, Geslot R (1986) Residual stresses measurements in plates by electrochemical machining of fine layers. CIRP Ann 35(1):409-412

20. Javadi Y, Smith MC, Abburi Venkata K, Naveed N, Forsey AN, Francis JA, Ainsworth RA, Truman CE, Smith DJ, Hosseinzadeh F, Gungor S, Bouchard PJ, Dey HC, Bhaduri AK, Mahadevan S (2017) Residual stress measurement round robin on an electron beam welded joint between austenitic stainless steel $316 \mathrm{~L}(\mathrm{~N})$ and ferritic steel P91. Int J Press Vessel Pip 154:41-57

21. Dreier S, Denkena B (2014) Determination of residual stresses in plate material by layer removal with machine-integrated measurement. Proc CIRP 24:103-107

22. Ekmekçi B, Ekmekçi N, Tekkaya AE, Erden A (2004) Residual stress measurement with layer removal method, Proceedings Of the First Cappadocia International Mechanical Engineering Symposium, 1, p. 9

23. Hofmann M, Gan W, Rebelo-Kornmeier J (2015) STRESS-SPEC: materials science diffractometer, Journal of large-scale research facilities JLSRF, 1

24. Brokmeier H-G, Gan WM, Randau C, Völler M, RebeloKornmeier J, Hofmann M (2011) Texture analysis at neutron diffractometer STRESS-SPEC. Nucl Inst Methods Phys Res A 642: $87-92$

25. Noyan IC, Cohen JB (2013) Residual stress: measurement by diffraction and interpretation. Springer

26. Jiang W, Luo Y, Wang B, Woo W, Tu ST (2015) Neutron diffraction measurement and numerical simulation to study the effect of repair depth on residual stress in 3161 stainless steel repair weld. J Press Vessel Technol 137(4):041406

27. Rebelo-Kornmeier J, Hofmann M, Gan WM, Randau C, Braun K, Zeitelhack K, Defendi I, Krueger J, Faulhaber E, Brokmeier HG (2017) New developments of the materials science diffractometer STRESS-SPEC. Mater Sci Forum 905:151-156

Publisher's note Springer Nature remains neutral with regard to jurisdictional claims in published maps and institutional affiliations. 